\title{
Starting at the Beginning: The Concerns and Needs of New Faculty
}

\section{Jim L. Turner and Robert Boice}

California State University, Long Beach

Evidence continues to accumulate indicating that professors view the rewards of academic careers as diminishing. The recent Carnegie Foundation survey of over 5000 faculty members revealed that 40 percent saw morale in their departments as worse than it was five years ago, 40 percent experienced a declining enthusiasm for their work, and over half considered leaving academe (Jacobson, 1985).

To the extent that faculty development programs address this morale problem, they often focus on middle-aged, disillusioned professors (Boice, 1986). We readily assume that morale is fine among beginning assistant professors. And, we generally ignore the processes which affect morale for good or ill.

Studies of academic careers indicate that job satisfaction decreases from career onset until just before retirement, at which time it increases (Baldwin \& Blackburn, 1981). There is some indication that this pattern is not gradual and linear, but includes predictable peaks and valleys associated with periods of career stability and transition. Most studies of academic careers, however, are cross-sectional in design and rely largely on a single interview or questionnaire.

In fact, we know surprisingly little about how faculty attitudes, beliefs, and behaviors change over time. This study describes the first year of a longitudinal project that tracks the course of these processes in new faculty. 


\section{PROJECT OBJECTIVES AND DESIGN}

Beginning in the fall semester of 1985, we initiated an intensive longitudinal study of all newly hired faculty at a large state university. Although we focus primarily on beginning assistant professors with tenure track appointments, we also collect data on experienced newly appointed faculty and new full-time lecturers. Participation in the study is strictly voluntary; we assure all participants that they will remain anonymous and that all data will be used only for research purposes.

To date, over 95 percent of the $100+$ individuals contacted have agreed to participate in the study, and most have been exceptionally cooperative. Approximately 70 new full-time faculty are currently being hired each year at the campus under study, and we will continue to add new sample members as time and other resources permit.

Our study aims at providing systematic ongoing documentation of (a) work habits, (b) teaching effectiveness, (c) scholarly productivity, (d) level of involvement in and enjoyment of various professional activities, (e) short-term objectives, (f) longterm career goals and aspirations, (g) critical incidents and/or other sources of satisfaction/dissatisfaction, and (h) other assorted attitudes, values, and behaviors. In addition, we are actively intervening with a randomly selected subsample of new faculty to help them effect a balance among demands for scholarship, teaching, and professional well-being.

The methods of data collection employed include a series of interviews, direct observation in both classroom and office, and self-observations by faculty in the form of structured journals, logs, and ratings. We are studying faculty at two levels of depth. All new faculty complete the structured interviews that appear in Appendices A, B, and C, during their first, second, and third semesters on campus. Ten new faculty randomly chosen from each year's cohort are invited to volunteer for more intensive, weekly visits by the researchers to offices and classrooms. Prior to the first rating session the authors carried out a series of pilot observations to insure agreement and reliability of ratings. We take turns alternating weekly visits to the classrooms and offices of new faculty. During these visits, we rate selected teaching behaviors (in the classroom) and assess several general and personal behaviors of interviewees (Appendix D). Except where a frequency count 
is entered, we make 1-10 judgments of appropriateness (where 10 is most appropriate and ideal) on these rating sheets. Items on the rating scale pertaining to classroom performance come from current synopses of effective teaching behaviors (e.g., Brophy, 1986; Cuseo, 1986). Ratings of selected behaviors during office visits provide an ongoing record of variations in work-related attitudes and overall morale. New faculty in this subgroup also keep daily records of time utilization (Appendix E).

\section{SAMPLE CHARACTERISTICS}

The sample reported on here consists of 66 faculty hired for the fall semester of 1985 . The majority of these new faculty (79 percent) have Ph.D. degrees, the remainder have master's degrees (e.g., M.A., MSW, MFA, etc.). The average age is approximately 34 (range $=27-54$ ); 67 percent received their highest degree within the past five years. Sixty-two percent are male, 38 percent are female. Half were appointed in tenure track positions, half to full-time lecturer positions. This sample is heterogeneous with regard to discipline, with nearly all schools on campus represented.

\section{RESULTS}

Our first year of study showed that new faculty arrived with high expectations regarding the quality and quantity of collegial interaction they would experience. They anticipated an intellectually stimulating and supportive environment with frequent informal interactions about scholarly issues, teaching, and other professional matters. They expected their senior colleagues to be active mentors who would serve as good role models and as a source of constructive advice and encouragement. Frustration of these expectations produced the greatest number of reports of professional dissatisfaction.

Most new faculty reported that the low levels of intellectual companionship they encountered were crucial deterrents to their own performance, morale, and long-term professional development. Despite their expressed desire for collegial interaction, new faculty in their first year were not themselves proactive in this regard. They rarely initiated informal professional interaction with colleagues and rarely sought advice or 
mentoring from senior colleagues. By the end of the first semester, nearly a third of the new faculty purported to have given up on their colleagues and asserted that their only source of intellectual stimulation and companionship would derive from interactions with students.

New professors in this sample reported that their workweek averaged 55+ hours. Fifty percent rated themselves as being the busiest they had ever been in their lives; 85 percent reported experiencing significant job-related stresses, symptoms of which included acute anxiety attacks, chronic sleep disturbance, loss of self-confidence, and frequent mood shifts.

The self-reported and observed work time of these new faculty in their first year was largely devoted to teachingrelated activities. The majority of their workweeks was used in preparing for their classes. This often results in a syndrome which might be termed "assistant professoritis"-i.e., new faculty overprepare, feel compelled to teach everything they know, provide little time or incentive for student participation, impress students as aloof and unapproachable, receive poor student evaluations, and blame this outcome on the poor quality of students in their classes.

Although new lecturers had a heavier teaching load than their tenure track counterparts $(\mathrm{X}=12.6$ hours/week vs. $\mathrm{X}=8.8$ hours/week, respectively), lecturers received higher student evaluations and rated themselves as experiencing greater personal satisfaction than did tenure track faculty.

When asked to describe their most positive experience since arriving on campus, new faculty (both lecturer and tenure track) most frequently reported a particular incident illustrating the rewards of teaching. For example, new faculty expecially cherish recollections of students who offered praise such as claims that they found a class stimulating, perhaps the best class they had taken. In general, the teaching concerns of inexperienced new faculty continue to revolve around the following questions: How formal/informal should I be in my relations with students? What is the optimal level of student classroom participation, and how do I achieve it? How do I gauge students' level of understanding? How can I spend less time preparing for my courses and still do a good job? Why does teaching require so much time?

The new faculty on our study campus told us that they 
hoped to spend 50 percent of their time on their own research and scholarship, but estimated that they would actually spend about 30 percent. In fact, they spent less than 15 percent so engaged during their first year. Indeed, most new faculty fell significantly short of their own stated objectives for scholarly productivity.

While nearly all anticipated completing at least one paper by the end of the first year, the modal number of papers finished was zero. Despite their heavier teaching load, new lecturers were as productive, in terms of papers presented at professional meetings and articles submitted for publication, as new tenure track faculty. Although reasons for this paradoxical finding remain unclear, teaching load does not predict scholarly productivity as well as supposed (Boice, in press).

New faculty (like many of their more senior colleagues) in this study strongly believe that creative scholarship, especially writing, requires large blocks of free time. During their first year on campus they made little effort to write at regular, brief intervals; instead, they felt that writing had to be done at home where they would be undisturbed. The result was procrastination and little scholarly writing.

\section{DISCUSSION}

This ongoing study indicates that new faculty in our sample are experiencing significant job-related stress. These newcomers discovered that their relationships with senior colleagues were not likely to be as supportive and stimulating as they expected. This finding is consistent with reports such as Fink's (1984) account of new faculty in geography, which makes similar points about the lack of anticipated collegiality and the negative effects of that deficit.

During their first semesters many new faculty in our sample received less than satisfactory student evaluations of their teaching. This unanticipated outcome, combined with the sense of isolation just mentioned, became a source of considerable distress and confusion.

Furthermore, by the end of the first year the majority of new faculty in our sample had devoted little of their time to creative scholarship and writing. Nearly all reported strong beliefs that productive scholarship is virtually impossible 
without a significant reduction in their teaching load. And nearly all new faculty on tenure tracks expressed concerns about meeting minimum requirements of scholarly activity established by University committees for retention, tenure, and promotion.

Perhaps because they feel vulnerable, new faculty seem especially receptive and responsive to appropriate faculty development services and programs. Some of our ongoing efforts in this regard include:

Collegiality: Encouraging new faculty to take a proactive role in forming small support groups; to attend faculty development workshops on coping skills and faculty development classes on physical fitness; to learn about the needs and concerns of new faculty and the importance of their own contributions to initial adjustment and morale; and to follow through on interdisciplinary contacts and possibilities for collaboration.

Teaching: Offering constructive, practical feedback about classroom and office performance based on our direct observations and on student commentary; encouraging faculty to solicit peer observation of their teaching; and urging them to sit in on the classes of their colleagues.

Scholarship/Writing: Providing a series of workshops on scholarly writing; establishing support groups for writers; encouraging individuals to make writing a less painful, more public activity; working intensively with individuals who experience writing blocks and other hindrances to productivity.

Mentoring: Implementing a mentoring program for new faculty in which we assume a proactive role in establishing supportive relationships between senior faculty and their new colleagues. We begin with the assumption that mentoring is a crucial component of successful faculty careers (e.g., Sorcinelli, 1985; Wylie, 1983). In essence, our program emphasizes coteaching as the medium for structured and sustained interactions between faculty new to teaching and senior colleagues who excel at teaching and at balancing the demands for scholarship with teaching activities.

We believe that the success of all of these interventions hinges on the willingness of faculty developers to seek out new faculty, to become familiar with their individual needs and concerns, and, ultimately, to demonstrate that intervention programs can be of benefit. In an active role, faculty developers 
can help improve collegial relationships, enhance comfort and performance in the classroom, promote scholarly productivity, and help facilitate other professional activities vital to successful careers in academe.

\section{REFERENCES}

Baldwin, R. G., and Blackburn, R. T. (1981). The academic career as a developmental process. Journal of Higher Education, 52, 598-614.

Boice, R. (1986). Faculty development via field programs for middle-aged, disillusioned faculty. Research in Higher Education, 25, 115-135.

Boice, R. (in press). Is released time an effective component of faculty development programs? Research in Higher Education.

Brophy, J. (1986). Teacher influences on student achievement. American Psychologist, 41, 1069-1077.

Cuseo, J. (1986). Effective college teaching: Research and practice. Unpublished handout. Department of Psychology, Marymount College, Rancho Palos Verdes, CA 90274.

Fink, L. D. (1984). First year on the faculty: Being there. Journal of Geography in Higher Education, 8, 11-25.

Jacobson, R. L. (1985). New Carnegie date show faculty uneasy about the state of academe and their own careers. Chronicle of Higher Education, 31(16), pp. 1, 24.

Sorcinelli, M. D. (1985, February). Faculty careers: Personal, institutional and societal dimensions. Paper presented at American Educational Research Association, Chicago.

Wylie, N. R. (1983). Helping new faculty adjust to careers at liberal arts colleges. FIPSE Grant Proposal submitted from Great Lakes Colleges Association, Ann Arbor, MI. 


\section{APPENDIX A}

\section{New Faculty Interview Schedule A}

\section{(administered during first semester on campus with new faculty)}

1. Career path

a. Briefly describe process by which you chose to accept a position at CSULB.

b. Other positions considered? Was CSULB your first choice? Ideally, what would have been first choice? (Rank order)

Small college with primary emphasis on undergraduate teaching

State college or university with equal emphasis on teaching and research

_ Major university with primary emphasis on research and graduate level teaching

Other

c. What were major factors in choosing CSULB? (Rank order) colleagues/quality of department location

opportunities for scholarship

_ primary interest in teaching

salary

no other jobs available other

d. Circumstances being the same and knowing what you know now, would you make the same choice again? Why, why not?

e. How long do you expect to be here? less than 5 years

5 to 10 years

10 to 15 years

- entire career

f. If you expect to leave, what are the anticipated reasons?

2. General impressions of CSULB

a. Quality of facilities and support services (e.g., classrooms, secretarial help, resources necessary for scholarship/research)

(1) excellent

(2) good

(3) average

(4) poor

Elaborate on why. 
b. (1) Initial impressions of colleagues and/or other faculty helpful and supportive: very much somewhat not very Any examples?

(2) Initial impressions of administrators helpful and supportive: very much Any examples?

c. What sort of advice, if any, have you received from colleagues? (solicited or unsolicited)

d. What is your impression of your colleagues' attitudes toward CSULB? What do they say are the good and bad points of their work lives here?

e. Do you anticipate collaborating in research and/or coteaching courses with any colleagues? (Probe for specific plans.)

f. In general, how important is a positive sense of collegiality to your own sense of well-being and job satisfaction?

very important somewhat important not very important

g. What factors do you view as of particular importance in facilitating your personal growth and development as a university professor? What have been your most positive experiences so far?

h. Have you had any negative experiences or incidents so far (e.g., broken promises, interpersonal conflict, etc.)? Source of negative experience; department chair, colleagues, administrators, other.

i. Initial impressions of quality of students.

How do students here compare to those on other campuses with which you are familiar?

3. Self-Assessment of Teaching Philosophy and Skills

a. Could you briefly describe your teaching philosophy? What are the values which guide your approach to classroom teaching, your expectations of yourself and students?

b. How would you characterize the qualities of the best teachers you have known?

c. At this point, what do you believe are your major strengths and weaknesses as a teacher?

d. At this point, what do you believe are your major strengths and weaknesses in terms of being a productive scholar?

e. In general, how would you describe yourself as a college professor? I am . . .

4. Time Management

In general what percentages of your time do you expect to devote to:

classroom teaching Actual Ideal

advising/consulting

with students

research/scholarship

community service 
university service

teaching preparation

other

Ideally, would you devote more or less time to these activities?

What are other demands on your time? (family, etc.)

\section{Professional Development}

What are your immediate goals (this semester)?

Long term?

In what way could the Center for Faculty Development most benefit you in your professional and/or personal development?

Any particular programs or services that you would like to see offered?

\section{APPENDIX B}

\section{New Faculty Interview Schedule B \\ (administered at end of second semester for new faculty)}

1. Teaching:

a. Number of separate course preparations during first year:

b. Size of classes taught:

$$
\begin{aligned}
& (1-14)= \\
& (15-34)= \\
& (35-99)= \\
& (100+)=
\end{aligned}
$$

c. Overall student evaluations of courses were:
(1) excellent
(2) good

(3) satisfactory

(4) fair

(5) poor

d. Compared to other instructors in your department, how did students rate your overall effectiveness as a teacher?

(1) one of the most effective

(2) more effective than most

(3) about average

(4) not as effective as most

(5) one of the least effective

e. Overall level of personal satisfaction with teaching performance during first year:

$\begin{array}{llllllllllll}\text { extremely } & 1 & 2 & 3 & 4 & 5 & 6 & 7 & 8 & 9 & 10 & \text { extremely }\end{array}$ dissatisfied satisfied

2. Collegiality:

a. Overall quality of interpersonal relationship amongst members of your department:
(1) excellent
(2) good
(3) satisfactory
(4) fair
(5) poor

b. Overall level of professional competence in your department: (1) excellent

(2) good

(3) satisfactory

(4) fair

(5) poor 
c. Overall performance of chairperson in your department:
(1) excellent
(2) good
(3) satisfactory

(4) fair

(5) poor

d. Overall level of intellectual companionship you have experienced here at CSULB?
(1) excellent
(2) good
(3) satisfactory
(4) fair
(5) poor

e. Found a mentor yet? yes

no

f. Extent to which above factors (i.e., personal and professional qualities of colleagues, access to intellectual companionship) have affected your own performance:

(1) extremely important

(2) somewhat important

(3) not important

3. Work Environment:

a. In general, where are you most likely to do the following kinds of work, at home or your office?

(1) Preparing lectures or other materials for your classes:

Home

Work

(2) Grading exams, homework, or term papers:

Home

Work

(3) Professional reading:

Home

Work

(4) Writing:

Home

Work

(probe "why?" for preferences)

b. Approximately how many hours per week are you actually on campus?

c. How similar is CSULB to school you attended as an undergraduate?

(1) very similar

(2) somewhat similar

(3) very dissimilar

d. How similar is CSULB to school you attended as a graduate student?

(1) very similar

(2) somewhat similar

(3) very dissimilar

e. Which is closest to your ideal of what an academic environment should be---which do you identify with most?

(1) undergraduate institution

(2) graduate institution

(3) CSULB 
f. To what extent have your experiences as a professor here at CSULB been congruent with what you expected?

(1) exactly what I expected, no surprises at all

(2) a few things were different from what I expected, nothing major or significant (probe)

(3) there were a few major surprises, things that did not turn out the way I expected (probe)

(4) it's been very different from what I expected (probe)

g. Overall, how would you characterize your general level of busyness during your first year at CSULB?

(1) extremely busy, perhaps the most busy I've ever been in my life

(2) very busy, never seem to get caught up, a source of stress

(3) somewhat busy, but manageable, no major anxieties or concerns about it

(4) not all that busy

(probe for elaboration of response, examples, etc.)

h. Considering everything you've experienced in your first year at CSULB, how would you rate your overall level of job satisfaction? $\begin{array}{llllllllllll}\text { extremely dis- } & 1 & 2 & 3 & 4 & 5 & 6 & 7 & 8 & 9 & 10 & \text { extremely satis- }\end{array}$ satisfied; would fied; it's exactly like to leave what I want to be doing

i. (as relevant) There was a series of workshops offered for new faculty this spring. Could you tell my why you did not participate in any of them?

(1) too busy

(2) time conflict with other activities

(3) didn't know about them

(4) didn't find them relevant or interesting

(5) other

4. Scholarly accomplishments this year:

a. Papers presented at professional conferences/conventions, etc.

b. Papers submitted for publication:

c. Papers published or accepted for publication:

d. Papers in progress/expected time of completion and submission:

e. Writing plans for immediate future (i.e., over summer, etc.):

f. Research proposals submitted:

g. Overall level of personal satisfaction with scholarly accomplishments during first year:

$\begin{array}{llllllllllll}\text { extremely } & 1 & 2 & 3 & 4 & 5 & 6 & 7 & 8 & 9 & 10 & \text { extremely }\end{array}$ dissatisfied satisfied 


\section{APPENDIX C}

\section{New Faculty Interview Schedule C (administered during the third semester for new faculty)}

Professional activities during the summer:

1. Teaching: Yes No NOTES:

2. Professional reading: Yes No NOTES:

3. Scholarly writing for publication: Yes No NOTES:

4. Other scholarly/research work (collect and analyze date, etc.) NOTES:

5. Prepare syllabi, lecture notes, etc. for fall semester:

Yes No NOTES:

On a ten-point scale, rate extent to which you achieved your goals for summer:

didn't achieve any

$$
\begin{array}{llllllllll}
1 & 2 & 3 & 4 & 5 & 6 & 7 & 8 & 9 & 10
\end{array}
$$

achieved all At this time, how would you rate your personal level of overall satisfaction/ dissatisfaction with:

\section{extremely dissatisfied}

extremely satisfied

The quality of students here at CSULB

$\begin{array}{llllllllll}1 & 2 & 3 & 4 & 5 & 6 & 7 & 8 & 9 & 10\end{array}$

Your teaching load

$\begin{array}{llllllllll}1 & 2 & 3 & 4 & 5 & 6 & 7 & 8 & 9 & 10\end{array}$

Your own teaching performance

$\begin{array}{llllllllll}1 & 2 & 3 & 4 & 5 & 6 & 7 & 8 & 9 & 10\end{array}$

The level of support and encouragement you have received from the university for scholarship/research

$\begin{array}{llllllllll}1 & 2 & 3 & 4 & 5 & 6 & 7 & 8 & 9 & 10\end{array}$

Your own scholarly/research accomplishments and productivity

$\begin{array}{llllllllll}1 & 2 & 3 & 4 & 5 & 6 & 7 & 8 & 9 & 10\end{array}$

The level of professionalism and commitment to academic excellence in your department

$\begin{array}{llllllllll}1 & 2 & 3 & 4 & 5 & 6 & 7 & 8 & 9 & 10\end{array}$

The attitudes and behaviors of senior colleagues toward new young faculty

$\begin{array}{llllllllll}1 & 2 & 3 & 4 & 5 & 6 & 7 & 8 & 9 & 10\end{array}$

The performance of your chairperson

$\begin{array}{llllllllll}1 & 2 & 3 & 4 & 5 & 6 & 7 & 8 & 9 & 10\end{array}$

To date, has anyone here at CSULB assumed an ongoing role as professional mentor to you? colleague ; chairperson ; assoc. dean/dean __., other ; no one 
So far, what has been the most personally rewarding and satisfactory aspect of your professional life here at CSULB?

So far, what has been the most disappointing or dissatisfactory aspect of your professional life here at CSULB?

What are your major goals this academic year with respect to:

Teaching:

Research/scholarship:

Other:

What is your best estimate of the percentage of your work time you will be devoting to research/scholarship in the course of this academic year?

How many hours per week actually writing (drafts of papers for publication, etc.)?

How will writing time be distributed (daily, weekends, etc.)?

How many hours per week collecting/analyzing data?

How many hours per week reading/reviewing literature in specialty area?

\section{APPENDIX D \\ New Faculty Rating Tracking Sheet}

Name Date Time Location

TEACHING CATEGORIES:

$\mathrm{CC}$

EN

$\mathrm{H}$

I/Q

MS

OC

$\mathrm{P}$

$\mathrm{P} / \mathrm{R}$

$\mathrm{R} / \mathrm{CS}$

$\mathrm{S}$

SA

SM

TD

Classroom comfort

Enthusiasm

Humor (frequency)

Interactions/questions

Management strategies

Organizational clarity and preparedness

Pacing

Previews/reviews

Rapport/communication skills

Spontaneity

Student attentiveness/task engagement

Switch made from theory to application, abstract to concrete Talking down

GENERAL OBSERVATION CATEGORIES:

$\begin{array}{ll}\text { A } & \text { Advocacy (frequency) } \\ \text { C } & \text { Complaints (frequency) } \\ \text { D } & \text { Disclosiveness } \\ \text { EG } & \text { Energy } \\ \text { EJ } & \text { Enjoyment } \\ \text { FR } & \text { Friendliness }\end{array}$


RS

SW

ST

$\mathrm{SC}$

$\mathrm{BO}$

Reactivity/suspicion

Spontaneous ref to scholarly writing

Spontaneous ref to teaching

Spontaneous ref to colleagues

\section{Burnout}

Note: Except when frequency tabulations are indicated, items are rated on a scale of 1 (lowest) to 10 (highest).

\section{APPENDIX E}

\section{New Faculty Self-Tracking Sheet (Robert Boice \& Jim Turner)}

Code name

Dates to

Code: for time arrows (please indicate work off campus parenthetically)
$\mathrm{B}=$ break
$\mathrm{C}=$ collegial interaction
$\mathrm{CM}=$ committee meeting
$\mathbf{G}=$ grading
$\mathrm{L}=$ lecture
$\mathrm{O}=$ office hour
$\mathrm{Ph}=$ phone

$\mathrm{P}=$ prep. for lecture

$\mathrm{R}=$ research $/$ creative work

$\mathrm{SR}=$ scholarly reading

$\mathrm{SW}=$ scholarly writing

$\mathrm{SS}=$ socializing with students

$\mathrm{SF}=$ socializing with faculty

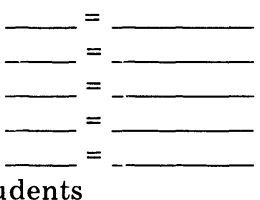

Code for rating intensity \& enjoyment: $1=$ least $10=$ most

\begin{tabular}{|c|c|c|c|c|c|c|c|c|c|c|}
\hline Day/ & \multicolumn{10}{|c|}{ Hour of Work Day } \\
\hline Date & 1 & 2 & 3 & 4 & 5 & 6 & 7 & 8 & 9 & 10 \\
\hline $\begin{array}{l}\text { 1 Sun } \\
\text { Date: }\end{array}$ & & & & & & & & & & \\
\hline $\begin{array}{l}2 \text { Mon } \\
\text { Date: }\end{array}$ & & & & & & & & & & \\
\hline $\begin{array}{l}3 \text { Tues } \\
\text { Date: }\end{array}$ & & & & & & & & & & \\
\hline $\begin{array}{l}4 \text { Wed } \\
\text { Date: }\end{array}$ & & & & & & & & & & \\
\hline $\begin{array}{l}5 \text { Thur } \\
\text { Date: }\end{array}$ & & & & & & & & & & \\
\hline $\begin{array}{l}6 \text { Fri } \\
\text { Date: }\end{array}$ & & & & & & & & & & \\
\hline $\begin{array}{l}7 \text { Sat } \\
\text { Date: }\end{array}$ & & & & & & & & & & \\
\hline
\end{tabular}

